Resumo

A familia possui um papel de grande relevancia no desenvolvimento emocional da criança, é capaz de desempenbar um papel facilitador na compreensão de sua sintomatologia. O presente trabalho apresenta a entrevista familiar diagnóstica como uma técnica utilizada no processo de triagem infantil em uma clínica-escola a fim de facilitar a compreensão do caso atendido. Para tanto, apresentar-seá um caso clínico de uma criança de oito anos de idade, do sexo masculino, que foi atendida no Servicgo de Triagem e Atendimento Infantil e Familiar (STAIF) do Centro de Pesquisa e Psicologia Aplicada (CPA) da FFCLRP da Universidade de São Paulo (USP).

Palavras-chave: clinica-escola; triagem infantil; psicodiagnóstico interventivo.

\section{ENTREVISTA FAMILIAR COMO FACILITADORA \\ NO PROCESSO DE TRIAGEM DE UMA CLÍNICA ESCOLA}

\author{
Andressa Pin Scaglia ${ }^{1}$ \\ Fernanda Kimie Tavares Mishima ${ }^{2}$ \\ Valéria Barbieri ${ }^{3}$
} Psicóloga voluntária do Departamento de Psicologia
e Educação da Faculdade de Filosofia, Ciências
e Letras de Ribeirão Preto da Universidade de São Paulo (FFCLRP-USP).

- Psicóloga do Centro de Pesquisa e Psicologia Aplicada

(CPA) do Departamento de Psicologia e Educação da Faculdade de Filosofia, Ciências e Letras de Ribeirão Preto da Universidade de São Paulo (FFCLRP-USP). Doutoranda do Programa de Pós-Graduação em Psicologia da Faculdade de Filosofia, Ciências e Letras de Ribeirão Preto da Universidade de São Paulo (FFCLRP-USP).

- $\square$ Docente do Departamento de Psicologia e Educação da Faculdade de Filosofia, Ciências e Letras de Ribeirão Preto da Universidade de São Paulo (FFCLRP-USP). 


\section{Introdução}

A s dificuldades psicológicas presentes na infância podem acompanhar o indivíduo ao longo de sua vida e, por vezes, até se agravar. Desta forma, entende-se como de grande importância uma abordagem e intervenção precoce dos sintomas presentes no início da vida. Tendo em vista o objetivo de atender a tal necessidade, criou-se na clínica-escola de Psicologia da Universidade de São Paulo, campus Ribeirão Preto, o "Serviço de Triagem e Atendimento Infantil e Familiar" (STAIF) (Mishima, Pavelqueires, Parada \& Barbieri, 2009).

O STAIF atua desde a chegada do paciente até seu encaminhamento, Nesta abordagem, entende-se como essencial não só o contato com a criança, mas também com sua própria família. A triagem de cada caso consiste em cinco sessões: entrevista inicial com os pais da criança, sessão lúdica com a criança, entrevista familiar diagnóstica com todos os moradores da casa e duas sessões de devolutiva, uma com os pais e outra com a criança. É uma forma prolongada de triagem que prioriza o uso de instrumentos abertos e não diretivos. Este processo possibilita a expressão das fantasias inconscientes de enfermidade e cura do paciente, como permite avaliar os recursos e limitações de seus pais, tanto individualmente, quanto no grupo familiar. A sintoma- tologia da criança é avaliada de maneira ampla, ou seja, dentro do contexto das relações familiares, em que é possível discriminar os mecanismos projetivos e introjetivos nelas presentes. Tais informações possibilitam identificar quem é o paciente real mesmo quando este não apresenta os sintomas (Barbieri, 2008).

Entende-se que a possibilidade de uma avaliação mais profunda da criança e de sua família permite um encaminhamento mais consistente. Segundo Berger (1989), geralmente no contato inicial com o terapeuta, na primeira consulta do filho, os pais se mostram confusos frente ao que entendem como "sintoma". Diante desta situação, o profissional tende a propor um quadro pré-concebido ou, ainda, a diferenciar muito rapidamente a dinâmica psíquica e encaminhar a criança para a psicoterapia individual. Desta forma, o profissional acaba por não abordar as questões comuns aos membros da família, as zonas de indiferenciação familiares e as zonas patológicas comuns, questões importantes para o progresso positivo do processo terapêutico.

Ao contrário desta tendência, o processo de triagem utilizado pelo STAIF visa justamente delinear um quadro mais amplo. Trata-se de um processo interventivo, baseado na vertente do "Psicodiagnóstico Interventivo de Orientação Psicanalítica". Optou-se por uma ação interventiva para que o indivíduo possa ocupar uma posição não só de "objeto de 
estudo", mas para se beneficiar do processo (Barbieri, 2008).

A situação de psicodiagnóstico leva o paciente a expressar de maneira mais rápida e direta seus conflitos. O Psicodiagnóstico Interventivo, por meio de uma aliança investigativa e interpretativa, possibilita que, durante todo o processo investigativo, o profissional faça interpretações e assinalamentos, oferecendo suporte emocional ao paciente. Desta forma, o potencial da situação diagnóstica para elucidar aspectos centrais da personalidade do indivíduo é trabalhado conjuntamente (Barbieri, Jacquemin \& Biasoli-Alves, 2007). Esse processo implica em mostrar ao cliente a situação que ele apresenta de um novo modo, promovendo uma desestruturação momentânea das percepções antigas e reorganizações perceptuais, em que novas opções de vida poderão ocorrer (Advíncula \& Gomes, 1999).

Diferentemente da visão clássica do psicodiagnóstico, a estratégia utilizada (entrevistas e sessões lúdicas) insere os familiares no processo de triagem. Segundo Aberastury (1986), é muito importante que se consiga comparar os dados apresentados pelos pais com os obtidos durante a análise da criança, para avaliar as relações pais/filho.

Não é simples para os pais recorrerem a qualquer tipo de ajuda externa diante de problemas internos da família. Quando os pais o fazem é porque entendem que o ambiente fa- 
miliar não consegue solucionar os sintomas da criança, o que desperta neles ansiedades e angústias. Tal situação pode fazer com que eles levem seus filhos para atendimento mobilizados não só pelo desejo de pedir ajuda, mas, também, por ansiedades persecutórias e depressivas diante da dificuldade de contato com a criança. Nesse sentido, é importante que o profissional não só seja continente às necessidades destes pais como também lhes dê espaço para pensarem, cooperarem e se apropriarem da avaliação/atendimento. Esta participação ativa dos pais pode deixá-los mais estimulados a utilizarem seus recursos (Safra, 2001).

A entrevista inicial com os pais, em especial com a presença de ambos, possibilita um maior entendimento da criança, já que apresenta conteúdos emergentes do grupo familiar. O processo de triagem também considera a presença individual da criança, durante a sessão lúdica. Esta sessão tem a finalidade de conhecer a realidade infantil, pois é um espaço em que se possibilita o aparecimento da fantasia inconsciente de doença/cura. Entende-se que o surgimento tão imediato destas fantasias é devido ao temor a que se repita a conduta negativa dos objetos originários provocadores da enfermidade/ conflito (Aberastury, 1986).

Posterior à entrevista inicial, que conta com a participação dos pais, há outro momento em que a família se insere no processo de triagem. Nes- te, os pais, bem como todo o restante dos membros familiares que moram na casa da criança, são convidados a compor a sessão de entrevista familiar diagnóstica (EFD). Segundo Soifer (1983), a entrevista do grupo familiar é uma importante ferramenta de diagnóstico em psicologia infanto-juvenil, tem como intuito estabelecer um diagnóstico e um prognóstico consistente. Tal prática usa brinquedos e materiais de expressão que ampliam a dinâmica da entrevista. Desse modo, as sessões familiares proporcionam uma maior compreensão do conflito, pois nelas se evidencia o estilo de interação qeu reflete a maneira como a família transmite os ensinamentos para os filhos e, assim, podem favorecer a patologia observada. É, portanto, um momento em que é possível a observação da dinâmica familiar por meio não só da observação direta da relação e fantasias familiares, mas, também, pela transferência estabelecida com o terapeuta (Franco \& Mazorra, 2007). Além disso, a entrevista familiar proporciona ao profissional o motivo manifesto e o latente da queixa. Entende-se como motivo manifesto o sintoma que preocupa quem solicita o atendimento, já o latente é mais profundo e relevante, geralmente emerge no decorrer das sessões de psicodiagnóstico (Arzeno, 1995).

Berger (1989) aponta para o fato de que um dos aspectos importantes para o progresso da psicoterapia com crianças é a motivação desta em se 
desvencilhar das projeções às quais é objeto dentro da dinâmica familiar. $\mathrm{O}$ distanciamento e elaboração destas projeções são compreendidos como sucesso na terapia, mas, muitas vezes, é tido pelos pais como um movimento negativo. Tal situação se dá devido a não elaboração dos pais de suas próprias fantasias e projeções que alcançam seu filho, que, por vezes, acabam barrando/interrompendo o processo terapêutico da criança. Desta forma, a sessão familiar representa um momento de grande importância para o posterior sucesso terapêutico, pois um de seus objetivos é permitir um espaço para que os pais apresentem seus dinamismos e se responsabilizem diante do quadro sintomático do filho.

A última etapa do processo de triagem interventiva, realizada pelo STAIF, corresponde à devolução de informação, tanto com os pais quanto com a criança. A devolutiva tem como principal objetivo a transmissão, a restituição de informação diagnóstica e prognóstica discriminada e dosificada, relacionada com a capacidade egóica dos destinatários. Ressalta-se, também, a possibilidade de se observar a resposta verbal e pré-verbal do paciente e de seus pais diante da recepção da mensagem do psicólogo, informação esta que possibilita uma síntese acertada do caso e a emissão de um diagnóstico/prognóstico com maior base de certeza, na busca de oferecer um atendimento terapêutico mais adequado (Ocampo, Arzeno 
\& Piccolo, 1974/1995). Para realizar a devolutiva com a criança, o terapeuta recorre ao uso de estórias, criadas a partir de informações recebidas durante o processo de triagem. Esta forma de comunicação com a criança advém da possibilidade de comunicação pela área transicional, que possibilita o desenvolvimento emocional, ou seja, a formação do sintoma ocorre devido às dificuldades na elaboração de conflitos psíquicos vivenciados (Winnicott, 1979/1983).

No momento da devolutiva com os pais são abordados os principais aspectos referentes ao funcionamento psicodinâmico da criança, considerando sua inserção no ambiente familiar. Pretende-se, com isso, compreender o grupo e incluir a família no prognóstico da criança. Isso se deve à importância da participação dos pais, pois a eficácia do Psicodiagnóstico Interventivo depende das características do ambiente familiar (Ancona-Lopez, 1995). Nesse sentido, se houver flexibilidade e condições de modificação por parte dos pais, o método pode ser suficiente, sem a necessidade de atendimento psicoterápico posterior.

Diante de todas essas considerações, torna-se relevante considerar o papel desempenhado pela família no desenvolvimento emocional da criança, como forma de compreender sua sintomatologia e as possibilidades que o ambiente familiar oferece. Além disso, torna-se mais eficiente o encaminhamento e tratamento psicológico posterior do filho, pois os pais terão importante papel e possibilidade de participação no processo.

A fim de exemplificar esta linha de pensamento, o presente estudo apresenta o caso clínico de uma criança de oito anos de idade, do sexo masculino, que foi atendida no Serviço de Triagem e Atendimento Infantil e Familiar (STAIF) do Centro de Pesquisa e Psicologia Aplicada (CPA) da Universidade de São Paulo, campus de Ribeirão Preto.

\section{Caso clínico}

\section{Entrevista inicial: breve relato e análise}

$\operatorname{Davi}^{1}$ (31 anos) e Thaís (26 anos) moram com seus dois filhos: Diego (8 anos) e Jonas (3 anos). Eles procuraram o STAIF em busca de atendimento psicoterápico para Diego, trazendo como queixa 
seu medo excessivo: do escuro, de ficar sozinho, de se adaptar a novas situações.

No período atual, os pais afirmaram que Diego tem dificuldade de se relacionar com outras crianças, dificuldade para encarar novas situações, medo de escuro e de ficar sozinho. Sempre que o garoto não quer fazer algo "ele chora muito e não dá um motivo". Foi dito também que o garoto diz ver pessoas mortas. Quando isso acontece, a mãe responde: "Quem vê essas coisas de gente morta é porque faz. coisa errada". Outra queixa relatada foi a dificuldade de se concentrar nas brincadeiras: "ele brinca no máximo 15 minutos com os brinquedos e já larga". Relataram também que o nascimento do irmão parece ter despertado nele a vontade de brincar com brinquedos mais infantis.

Sobre a concepção da criança, a mãe contou que teve uma gravidez complicada, ficou de repouso durante os três primeiros meses devido a uma incompatibilidade sanguínea (eristoblastose fetal). Além deste problema, afirmou que foi um momento difícil, pois sentia muito ciúmes do marido, chegando a agredi-lo fisicamente. Apesar destes problemas, Thaís pontuou que cada novidade da gravidez era bastante comemorada. No final da gestação ela apresentou um quadro de trombose. Diego nasceu de cesárea, com 37/38 semanas, com algumas complicações: o cordão umbilical no pescoço, batimentos cardíacos acelerados e com hipoglicemia, tendo que permanecer por algumas horas na incubadora. Devido à trombose da mãe, a criança recebeu alta antes dela e ficou aos cuidados da avó paterna: "Ninguém no hospital acreditava que en pedi para levar men filho embora, tinha medo de não conseguir dar conta". A avó paterna foi a cuidadora mais próxima durante os primeiros meses de vida de Diego. Por conta dos fortes remédios para trombose, Thaís sentia muito sono e, certa vez, o marido chegou do trabalho e se deparou com Diego chorando nos braços da mãe que estava deitada na cama dormindo profundamente.

Diego foi amamentado no peito somente na primeira semana de vida. Os pais afirmaram que até hoje Diego toma diariamente 2 litros de leite. A mãe, ao amamentar, sentia-se muito nervosa por não conseguir, não tinha paciência porque ele chorava muito; o pai disse que ela tinha dó. Em seguida, o pai afirmou que a criança sempre foi muito acomodada, que se tem alguém em casa ela pede para que preparem as coisas para ela. A mãe disse que a avó "dá tudo mastigado", mas que na casa da família não é assim que funciona.

Diego chupou chupeta, mas a mãe tirou; porém, ao nascer o irmão mais novo, ele voltou a chupar escondido, especialmente na casa de sua avó. Os pais relataram que Diego tem um paninho que não larga desde a infância, ele fica passando o pano na boca, apertando e, quando vai viajar, esconde o pano para a mãe não lavar, dizendo que tem o cheirinho dele. 


\section{Artigo}

Como a mãe trabalha fora, é ele quem cuida do irmão de três anos. Diariamente Diego chega da escola, toma banho, faz questão de fazer toda lição da escola antes do almoço (é um aluno exemplar com notas muito boas), almoça e cuida do irmão, o dia todo, até quando a mãe está em casa. Rotineiramente, prepara a mamadeira dele, dá banho, brinca, faz dormir. Somente quando o irmão dorme ele vai fazer suas próprias coisas, como jogar videogame. A mãe afirmou que ele tem muito cuidado com o irmão e que nunca reclamou em desempenhar tal tarefa. Ele sempre arruma seu quarto e seus brinquedos e vai mostrar para a mãe, pois gosta muito de ser elogiado.

A entrevista inicial trouxe informações que possibilitaram algumas hipóteses sobre o caso. Importante ressaltar que, como se tratam de hipóteses, elas poderão ou não ser confirmadas no decorrer das sessões do processo de triagem.

A sintomatologia da criança pareceu estar ligada à dinâmica familiar, uma vez que se trata de uma criança bastante exigida, tanto externa quanto internamente. $\mathrm{O}$ ambiente familiar parece não acolher suas necessidades, mostrando-se insuficientemente bom: a mãe tem dificuldades para perceber e atender às necessidades do filho desde a amamentação, com prejuízo no desempenho de seu papel materno e holding insuficiente (Winnicott, 1945/2000). Devido às dificuldades no exercício da maternagem, a mãe 
não contém as angústias da criança, exigindo que ela dê conta de suas próprias necessidades e se cuide. Dessa maneira, a exigência sobre o menino é grande, fazendo com que ele tenha responsabilidades de um indivíduo adulto. Para alcançar estas exigências e não frustrar os pais, Diego deixa de ser criança para se mostrar autôno$\mathrm{mo} /$ responsável, deixando pouco espaço para as vivências da transicionalidade e exigindo um desenvolvimento mental mais intenso que o emocional, dando indícios de funcionamento falso self.

\section{Sessão lúdica}

Diego chegou acompanhado de seu pai, sua mãe e seu irmão. Ao ser questionado sobre o conhecimento do por que estava ali, ele respondeu que não sabia. A psicóloga disse que seus pais contaram que ele sentia medo de algumas coisas. Neste momento, ele respondeu: "Sabe o que que é? Eu já fui assaltado, en era menor os ladrões levaram a minha bicicleta na frente de casa. Dai eu fiquei com trauma, sou traumatizado". A seguir, ficou um tempo em silêncio e logo mudou de assunto.

Ele foi em direção à caixa lúdica, abriu-a sozinho, olhou-a detalhadamente, tirou o jogo de palitos e convidou a psicóloga a jogar com ele. Ficou muito incomodado com um pequeno defeito de fabricação de um dos palitos e explicou a pontuação de cada cor de vareta. Durante o jogo começou a ventar, algumas folhas fizeram barulho, neste momento, o garoto se mostrou levemente assustado, dizendo: "Nossa ouvi um barulho, assustei, mas percebi que é só folha mexendo".

Em seguida, guardou todos os palitos e pegou o jogo de damas. Durante a partida, ele arrumava as peças que pareciam estar fora do lugar, com muito cuidado e atenção. Espontaneamente falava alguns palavrões durante o jogo toda vez que perdia alguma peça, mesmo quando estava em vantagem. Diego ouviu um barulho do lado de fora e se mostrou assustado, a psicóloga conversou com ele sobre o susto e ele respondeu: "Nada, en achei que tinha ouvido a voz do meu irmão, mas não é, ele é meio doido, achei que ele tivesse atravessando a rua". A seguir, conversaram sobre como é o relacionamento dos dois, Diego contou que eles se dão bem, mas que às vezes o irmão menor pega o chinelo para bater nele e ele sempre corre e pede ajuda para a mãe. Logo em seguida disse para a psicóloga: 
"Você se distraiu conversando, fez uma jogada errada". Ele venceu o jogo, guardou todas as peças e as levou para a caixa.

Pegou o jogo de "bolinhas de gude" e contou que na casa de sua avó tem uma jarra cheia delas. Disse que gosta muito de ir para lá, pois tem amigos e brinca muito. Ao final do jogo, guardou as bolinhas. Por fim, pegou as famílias (pequenos bonecos de pano com representação do pai, mãe, avós e dois filhos): uma negra e outra branca. Perguntou para a psicóloga com qual ela queria ficar, mas já afirmou que preferia a branca. Começaram a brincar. $\mathrm{Na}$ brincadeira as duas famílias eram vizinhas; a avó negra batia na casa da avó branca e era muito bem recebida, combinaram uma festa para todos. Os garotos, negros e brancos, brincavam juntos. Diego, por muitas vezes, fazia com que algum membro de "sua família" carregasse o bebê branco, que geralmente caía do colo. Em um momento disse: "Nossa, - bebê está chorando, não pára de chorar, vou levarpara a mãe, ela é surda, ela não ouve!". No final do jogo, a avó negra pediu para que a família branca cuidasse do bebê branco, pois precisava sair de casa. Ao ser sinalizado sobre o final da sessão, Diego prontamente parou a brincadeira para guardar as coisas e saiu tranquilamente para encontrar os pais na sala de espera.

A sessão lúdica trouxe um repertório de informações que embasa algumas hipóteses descritas anteriormente. É possível pensar que se trata de um caso com bom prognóstico, pois ao considerar a sessão como um todo, nota-se que houve uma gradação no brincar: a sessão inicia com brinquedos mais estruturados (como jogo de palitos e dama) e termina com jogos menos estruturados (bonecos) dentro de uma brincadeira mais simbólica. Este aspecto permite pensar que Diego inicialmente se mostra rígido e, com o passar da sessão, tem possibilidade de se expressar com maior espontaneidade e criatividade.

Durante a sessão houve uma significativa preocupação com o ambiente externo, particularmente com a família que o esperava na sala de espera, o que remete à ideia de um brincar não relaxado, preocupado com o que poderia estar acontecendo fora dali sem o seu controle. Parece se responsabilizar pelo que acontece fora, como maneira de controlar o ambiente e manter o desempenho na tarefa de cuidar do irmão menor. Esta responsabilidade o impede de viver seus próprios conflitos, particularmente de cunho edípico, uma vez que há uma necessidade maior de cuidar do irmão e de suprir a falta de cuidados que recebeu de sua família, principalmente de holding. Esta tarefa é de responsabilidade muito grande para uma criança de sua idade.

As responsabilidades de Diego, não condizentes com a maturidade possível de se alcançar em sua idade, faz com que sua espontaneidade seja acobertada por regras e fique preju- 
dicada. O momento em que ele achou melhor reinventar a brincadeira e entregou o bebê para a psicóloga cuidar pôde ser entendido como um pedido para ser cuidado, uma possibilidade de deixar a exigência pessoal e do ambiente de lado para permitir brincar e ser criativo, podendo ser criança.

\section{Sessão familiar}

A família toda (pai, mãe, irmão e Diego) compareceu à sessão. O irmão de Diego mostrou-se um pouco envergonhado no início. Logo, foi-lhes dito que poderiam usar o tempo de maneira livre e como quisessem, podendo usar ou não a caixa lúdica. Apresentou-se a caixa e toda a família foi em direção a ela, Diego foi quem teve a iniciativa de abri-la. A mãe sentou em uma cadeira grande e o resto da família ficou nas pequenas. O irmão afirmou que não queria brincar ('"não quero, não quero!') e todos ficaram em sua volta tentando convencê-lo, inclusive Diego. Em seguida, ele concordou em jogar damas e sentou no colo do pai, que lhe deu explicações e orientou o movimento das peças. A mãe ficava observando e por vezes dava alguma sugestão a Diego, que refutava argumentando que não seria uma boa estratégia. Durante o jogo, Diego disse alguns palavrões e não foi repreendido pelos genitores. Todos pareciam muito pacientes com

414 Estilos da Clínica, 2011, 16(2), 404-423 
o irmão menor, Diego se mostrou, por vezes, condescendente, não querendo comer as peças do irmão, já este parecia mais rigoroso e não permitia que ninguém fugisse das regras. Diego venceu o jogo, todos guardaram as peças no saquinho e ele sugeriu que jogassem o jogo dos palitos. $\mathrm{O}$ irmão viu o dado de ludo e pediu para jogar, Diego fez uma cara de desaprovação e disse: “ah, não", mas, por fim, acabaram jogando ludo.

Neste jogo, todos os familiares participaram e cada integrante era de uma cor. Deu-se bastante atenção ao garoto pequeno: em alguns momentos o estimularam a dizer o número do dado e andar as casas, em outros, Diego fez por ele, mesmo o pai dizendo de maneira calma para que ele deixasse seu irmão fazer sozinho. Em alguns momentos ele deixava, mas logo voltava a mexer a peça pelo irmão. O irmão pareceu bastante ansioso e, por vezes, irritado com a mãe, ele mal a deixava jogar o dado e já pegava para jogar, logo desistiu da brincadeira e foi em direção à caixa pegar os bonequinhos de plástico. Começou a brincar de guerra. O pai disse: "não se empolgue muito nessa matança". Diego às vezes dispersava e observava a brincadeira de seu irmão, mas isso não atrapalhava o jogo com os pais. Já na metade do jogo a mãe disse ter lembrado de uma regra, mas o pai não aceitou incorporá-la: "Ah, você que jogue assim, eu não vou". Ao término, ela lembrou de mais uma regra, até sugeriu para que jogassem novamente, mas foi ignorada. Diego venceu, seu pai afirmou que queria continuar para ver quem ficaria em segundo lugar.

Mais uma vez Diego sugeriu que jogassem palito, mas pegou a bola na caixa e ficou jogando para o pai, brincando de fazer gol. Ele se esforçava para pegar a bola que seu pai jogava de maneira difícil e forte. A mãe comentou com a psicóloga: "Nossa, eu fico louca quando esses três fazem isso na sala, hoje mesmo eu estava passando roupa e me segurei, o pequeno veio e derrubou a pilha de roupas passadas"; neste momento, o filho menor pegou uma espada e começou a brincar com a mãe, que não entrou na brincadeira.

Diego convidou todos para brincarem de alguma coisa diferente, o pai disse: "Você não queria jogar palitos?", Diego respondeu: "Não, não, palito é chato!". Em seguida, pegou as folhas e disse que ia desenhar, todos sentaram novamente em volta da mesinha. $O$ filho pequeno se levantou, pegou a bola e começou a jogar com a mãe, todos pararam e falaram para ele "vai mais longe, você está muito perto". Depois ele se juntou ao pai e ao irmão e começou a desenhar, todos desenhavam, exceto a mãe. Os pais perguntavam para Diego o que ele ia desenhar, o garoto ficava pensando em algo, mas não dizia nada. Em seguida, a mãe fez alguns pedidos para o filho menor desenhar. Enquanto isso, o pai esboçou um desenho para ele. Os pais sugeriram que Diego fizesse um de- 
senho bonito que ele tinha feito no caderno da escola, ele disse que não se lembrava, eles insistiram, mas Diego não se recordou. Neste momento, o pai se irritou e disse: "Pára de graça vai, você sabe muito bem o que estamos falando", Diego respondeu: "Ah, não sei... ah lembrei, é um super-herói". Continuaram desenhando e dando sugestões para o desenho dos garotos: "Não aperte o lápis Diego, fica feio". O desenho do pai foi uma cópia de objetos e personagens infantis. Ao término da sessão, o pai e os filhos arrumaram tudo, combinaram o horário da devolutiva e se despediram.

Por meio da sessão familiar, mais uma vez, é possível perceber a preocupação de Diego com o irmão, que se mostra como o centro das atenções da família. Nota-se, também, que, em diversos momentos, o pai se mostra infantilizado (não adere às regras, faz desenhos infantis copiados), parecendo não exercer o papel paterno, mas se igualando às crianças. A função de autoridade e vigilância parece ter sido desempenhada pela mãe, que, para tal, deixa de exercer os cuidados maternos (bolding) e se isola, olhando as brincadeiras sem se envolver.

Nota-se que o ambiente não parece facilitador do gesto espontâneo, como no ato de desenhar, em que os filhos eram direcionados a fazer determinados desenhos, a exemplo da cópia feita pelo pai. Pode-se entender, então, que há uma inibição do gesto espontâneo para atender as expectativas dos adultos e, com isso, ser aceito e amado.

\section{Sessões de devolutivas}

$\mathrm{Na}$ devolutiva com a criança foi-lhe contada uma estória intitulada: "O menino que tinha que ser grande". Nela se faz presente o dilema de um menino que tinha dúvidas se era um adulto ou uma criança. A dúvida era acarretada pelas responsabilidades diárias de "gente grande", cabendo ao personagem principal o cargo de realizar uma diversidade de tarefas em sua casa, atividades que não o deixavam feliz, mas sim muito preocupado em conseguir fazê-las. Por outro lado, o menino sentia algumas vontades típicas de criança, como, por exemplo, brincar e assistir desenhos. Vontades não concretizadas, pois ele tinha muito medo de que, caso fosse criança, perderia o amor das pessoas que amava, por decepcioná-las. Em 
um dia comum, este garoto dormiu, teve um sonho revelador e ao acordar teve a certeza de que era uma criança. Logo foi comunicar tal descoberta para todos que o rodeavam e, com a ajuda de seus pais e amigos, passou a se dedicar somente às questões infantis. Dessa forma, no decorrer do tempo, as responsabilidades foram surgindo, de acordo com o crescimento dessa criança.

Diego ouviu atentamente toda a estória, não quis comentá-la, mas aceitou com prontidão levá-la para casa. Em seguida, pediu para mexer na caixa e retirou um brinquedo bastante infantil, um aviãozinho com o qual brincou por alguns segundos. Deixou o avião de lado e escolheu um jogo no qual interagiu com a psicóloga.

Durante a entrevista devolutiva, primeiro, fez um desenho bem estereotipado (montanha com sol), na sequência, pegou outra folha e iniciou um desenho de um parque infantil. Em um momento desabafou: " $A h, e n$ não sei desenhar gira-gira, o meu fica feio". A psicóloga o incentivou a desenhar o que ele conseguisse e ele continuou. Dado o tempo da sessão, ele se despediu da terapeuta e saiu em direção à sala de espera, onde os seus familiares o aguardavam.

Devolutiva com a familia: Ao chamar os pais para a devolutiva, o irmão menor de Diego começou a chorar e dar socos na bolsa de sua mãe, afirmando que também queria entrar na sala. Diego, prontamente, tentou acalmá-lo, propondo-se a ler a estó- ria que acabara de receber. A mãe deu o celular para o garoto, que se acalmou e os pais puderam entrar na sala de atendimento.

Inicialmente a psicóloga destacou a responsabilidade que os pais tiveram frente às sessões, com sua presença e pontualidade. Afirmou que Diego recebeu uma estória como devolutiva, que pôde levá-la embora e, caso quisesse, os pais poderiam ler a estória para ele quando fosse solicitado. Já ali, com eles, a devolutiva seria uma conversa.

De maneira geral, a psicóloga pontuou sobre o excesso de responsabilidade depositado na criança, a probabilidade de seus medos advirem de não conseguir cumprir a pesada tarefa imposta e decepcionar seus pais, perdendo, assim, o afeto deles. Os pais concordaram que o garoto realmente possuía muitas responsabilidades. Pontuou-se, também, a dificuldade que Diego tinha em demonstrar criatividade e em ser espontâneo, que seu tempo de criança precisava ser respeitado, para permitir maior contato com o lúdico. Durante a conversa o pai afirmou não se preocupar muito com a situação de Diego: "É só uma fase, quando eu tinha a idade dele, eu era igual, bem medroso".

Ao final, a psicóloga apontou para algumas práticas educativas que poderiam ser pouco beneficiadoras do desenvolvimento emocional do garoto, como ser punido severamente, sem permitir a compreensão do que foi feito, ou ainda, exigir da crian- 
ça comportamentos e atitudes que ele não estava preparado para desempenhar. Foi proposto aos pais que participassem de um grupo de pais na própria instituição sobre "práticas educativas", eles aceitaram. O garoto foi encaminhado para psicoterapia na mesma instituição.

\section{Discussão}

Compreende-se que o processo de triagem para atendimentos psicoterápicos deve ser não só um momento de coleta de informações, mas, também, um período de reflexão e avaliação do cliente como um todo, sem deixar de ser um momento interventivo (Salinas \& Santos, 2002). De acordo com o exemplo clínico apresentado neste trabalho, pode-se afirmar que o STAIF faz uso de um método inovador de triagem, pois dá importância não só para a criança como também para toda sua família, com a função do processo avaliativo e terapêutico.

Neste contexto, fica evidente a importância da entrevista familiar para confirmar ou refutar as hipóteses sugeridas na entrevista com os pais e observadas na sessão lúdica, o que favorece um adequado encaminhamento do caso e inclusão da família no tratamento da criança. Tal aspecto favorece a participação dos pais e o sentido de responsabilidade, como forma de amenizar o sentimento de

418 Estilos da Clínica, 2011, 16(2), 404-423 
culpa e impotência diante da dificuldade da criança. Além disso, a sessão familiar também possibilita que genitores e filhos possam vivenciar a dinâmica e funcionamento psíquico presentes na vida cotidiana, facilitando a maneira de exemplificar e solicitar a inclusão dos pais no tratamento do filho.

No caso apresentado, a entrevista inicial de Diego levantou a hipótese de que sua sintomatologia era remetida ao ambiente familiar, dentro do qual ele é muito exigido; ambiente que parece não acolher suas dificuldades e não atender suas necessidades. Notouse também uma possível dificuldade no desempenho do papel materno (bolding insuficiente). Diante disto, faz-se necessário que o menino seja autônomo e, para tanto, deixe de lado suas vivências infantis de maneira a atender as exigências externas, o que ele entende como condição para ser amado.

A sessão lúdica ofereceu indícios de que se tratava de um caso com um bom prognóstico, pois Diego foi capaz de expressar sua espontaneidade e criatividade, apesar desta ser regrada pela preocupação e responsabilização com o ambiente externo. Neste momento as exigências em cumprir com as tarefas externas pareceram relacionadas à exigência interna e busca de aprovação do outro.

A sessão familiar expôs importantes informações que complementaram e confirmaram algumas hipóteses pontuadas nas sessões anteriores, como a inibição do gesto espontâneo, intensa preocupação com o irmão, a falta de uma figura que exerça o cuidado afetivo. A sessão esclareceu, porém, que a dificuldade no desempenho do papel materno pareceu ocorrer não somente devido à restrição por parte da mãe, mas sim diante da necessidade de que ela ocupasse o papel de autoridade, já que o pai apresentou uma postura infantilizada e pouco capaz de exercer tal função. Nesse sentido, ele se aproximou das crianças, permitindo que não aceitassem as regras do jogo, defendendo claramente a sua intenção de vencer as partidas e não tivessem que concordar com a mãe. $O$ pai também se mostrou pouco espontâneo, ao fazer desenhos copiados e sem criatividade, incentivando o filho a mostrar aquilo que sabia fazer e não o que queria fazer (bloqueando a espontaneidade da criança).

Ao final do processo de triagem foi possível compreender a sintomatologia da criança considerando a função da família e os aspectos psicodinâmicos nela envolvidos. As hipóteses dadas após a entrevista inicial com os pais e a sessão com a criança puderam ser confirmadas e melhor compreendidas pela sessão familiar. Além 
disso, ao devolver as informações aos pais houve o uso de exemplos do que ocorreu na sessão familiar, possibilitando o entendimento mais amplo. Também foi permitido aos pais que pudessem expressar suas opiniões e se comunicar com o terapeuta, sendo incluídos no universo infantil e responsabilizando-se pelo filho.

Entende-se, portanto, que o processo de triagem foi eficaz na identificação de psicodinamismos da criança e de seu ambiente familiar. Diversas questões foram abordadas com os pais ao final do processo e foi dado o encaminhamento do caso para atendimento na própria clínica-escola. Os pais seguiram o encaminhamento e o garoto já está sendo atendido há seis meses.

FAMILY INTERVIEW AS A FACILITATOR IN THE PROCESS OF SCREENING AT A SCHOOL CLINIC

\section{Abstract}

The family has a major role in the emotional development of children and is able to play a facilitating role in understanding their symptomatology. This work presents a family diagnosis interview as a technique used in the process of screening children in a school clinic to assist the understanding of the case attended. For this, it will be presented a clinical case of an eight-year-old male who was seen in the "Servico de Triagem e Atendimento Infantil e Familiar" (STAIF) of the Center of Research and Psychology (CPA) of FFCLRP of São Paulo's University (USP).

Index terms: clinical school; infant screening; therapeutic assessment. 
ENTREVISTA FAMILIAR COMO FACILITADOR EN EL PROCESO DE TRIAJE EN UNA CLINICA ESCUELA

\section{Resumen}

La familia tiene un papel de gran importancia en el desarrollo emocional del niño y es capaz de desempeñar un papel facilitador en la compreensión de su sintomatología. El presente trabajo muestra la entrevista familiar diagnostica como una técnica usada en elproceso de selección infantil en una clinica escuela com el objetivo de facilitar la comprensión del caso estudiado. Para esto se presenta un caso clínico de un niño de ocho años de edad que fue atendido en el "Serviço de Triagem e Atendimento Infantil e Familiar" (STAIF) del Centro Pesquísa y Psicologia Aplicada (CPA) de la FFCLRP de la Universidade de São Paulo (USP).

Palabras clave: clinica escuela, triaje infantil, psicodiagnostico interventivo.

\section{REFERÊNCIAS}

Aberastury, A. (1986). Adolescência (R. Cabral, trad.). Porto Alegre: Artes Médicas.

Advíncula, I. \& Gomes, P. (1999). O psicodiagnóstico interventivo em grupo para pais e crianças numa clínica-escola. Revista Symposium, 3, 10-22.

Ancona-Lopez, M. (1995). Psicodiagnóstico:processo interventivo. São Paulo: Cortez.

Arzeno, M. E. G. (1995). Psicodiagnóstico clínico: novas contribuições. Porto Alegre: Artes Médicas. 
Barbieri, V., Jacquemin, A. \& Biasoli-Alves, A. M. M. (2007). Psicodiagnóstico interventivo como método terapêutico no tratamento infantil: fundamentos teóricos e prática clínica. Psico, 38(2), 174-181.

Barbieri, V. (2008). Por uma ciência-profissão: o psicodiagnóstico interventivo como método de investigação científica. Psicologia em Estudo, 13(3), 575-584.

Berger, M. (1989). Prática das entrevistas familiares. Campinas, SP: Papirus.

Franco, M. H. P. \& Mazorra, L. (2007). Criança e luto: vivências fantasmáticas diante da morte do genitor. Estudos em Psicologia, 24(4), 503-511.

Mishima, F. K. T., Pavelqueires, J. G., Parada, A. P. \& Barbieri, V. (2009). Apresentação do serviço de triagem e atendimento infantil e familiar (STAIF) do Centro de Pesquisa e Psicologia Aplicada: uma experiência em formação. In N. Jesus, M. M. Rezende \& I. Leal (Orgs.), Experiências e intervenções em Psicologia da Saúde (pp. 596606). Faro, Portugal: Universidade do Algarve.

Ocampo, M. L. S., Arzeno, M. E. G. \& Piccolo, E. G. (1995). O processo psicodiagnóstico e as técnicas projetivas (M. Felzenszwalb, trad.). São Paulo: Martins Fontes. (Trabalho original publicado em 1974)

Safra, G. (2001). Procedimentos clínicos utilizados no psicodiagnóstico. In W. Trinca (Org.). Diagnóstico psicológico: prática clínica (pp. 51-66). São Paulo: EPU.

Salinas, P. \& Santos, M. A. (2002). Serviço de triagem em clínica-escola de psicologia: a escuta analítica em contexto institucional. Psychê, 6(9), 177-196.

Soifer, R. (1983). Psicodinamismos da família com crianças: terapia familiar com técnica de jogo (E. F. Alves, trad.). Petrópolis, RJ: Vozes.

Winnicott, D. W. (1983). O ambiente e os processos de maturação. (I. C. S. Ortiz, trad.). Porto Alegre: Artes Médicas. (Trabalho original publicado em 1979)

Winnicott, D. W. (2000). Desenvolvimento emocional primitivo. In D. W. Winnicott 


\section{Artigo}

(Org.), Textos selecionados: da pediatria à psicanálise (pp. 269-285). Rio de Janeiro: Francisco Alves. (Trabalho original publicado em 1945)

\section{NOTAS}

1 Todos os nomes dados aos participantes são fictícios, a fim de preservar sua identidade.

andressascaglia@yahoo.com.br fktmishima@srv1.ffclrp.usp.br valeriab@ffclrp.usp.br

Recebido em março/ 2010. Aceito em junbo/2011. 